\title{
LED illumination and plant growth regulators' effects on growth and phenolic acids accumulation in Moluccella laevis L. in vitro cultures
}

\author{
Sylwia Zielińska' ${ }^{1}$ - Ewelina Piątczak ${ }^{2}$ (1) $\cdot$ Weronika Kozłowska ${ }^{1}\left[\right.$ Aleksandra Bohater $^{5}$. \\ Anna Jezierska-Domaradzka ${ }^{1,4}$ (]) $\cdot$ Joanna Kolniak-Ostek ${ }^{3}$ (]) Adam Matkowski ${ }^{1,4}$
}

Received: 18 December 2019 / Revised: 31 March 2020 / Accepted: 4 April 2020 / Published online: 12 April 2020

(c) The Author(s) 2020

\begin{abstract}
Moluccella laevis L. (Lamiaceae) is an annual ornamental plant, naturally occurring in the areas of Western and Central Asia (Irano-Turanian area). It is a popular ornamental species, but its phytochemical profile remains poorly studied. This study presents the first report on in vitro cultures of M. laevis. The influence of two types of illumination and plant growth regulators (PGRs) supplementation on the morphogenetic response and the content of phenolic compounds were examined. Shoots were cultured on Murashige and Skoog (MS) solid basal medium. White light or photosynthetic active radiation (PAR) as well as three concentrations of 6-benzylaminopurine (BA) 2, 3 or $4 \mu \mathrm{M}$ and one of the three auxins: 1-naphthaleneacetic acid (NAA), indole-3-acetic acid (IAA) or 4-amino-3,5,6-trichloropicolinic acid (picloram-PIC) at concentration of $0.5 \mu \mathrm{M}$ were used for shoot proliferation. The highest number of axillary shoots per explant (3.4) was obtained for shoots grown on MS medium supplemented with 3- $\mu \mathrm{M}$ BA and $0.5-\mu \mathrm{M}$ NAA under PAR light. However, the effect of PGRs treatment on shoot growth and development was stronger than the influence of light. The phytochemical analysis using UltraPerformance Liquid Chromatography-Mass Spectrometry allowed identification of four hydroxycinnamic acids (caffeic, ferulic, rosmarinic, chlorogenic) and two cyanidin glycosides (cyanidin 3-O-galactoside, and cyanidin 3-O-malonylglucoside) in shoot clusters and callus tissue.
\end{abstract}

Keywords Irish bells $\cdot$ Shoot cultures $\cdot$ Phenolic acids $\cdot$ Light emitting diodes

Communicated by P. Wojtaszek.

Sylwia Zielińska

sylwia.zielinska@umed.wroc.pl

1 Department of Pharmaceutical Biology, Wroclaw Medical University, Borowska 211, 50-556 Wroclaw, Poland

2 Department of Biology and Pharmaceutical Botany, Medical University of Łódź, Muszyńskiego 1, 90-151 Łódź, Poland

3 Department of Fruit, Vegetable and Plant Nutraceutical Technology, Wroclaw University of Environmental and Life Sciences, ul. Chełmońskiego 37, 51-630 Wrocław, Poland

4 Botanical Garden of Medicinal Plants, Wroclaw Medical University, Al. Jana Kochanowskiego 10/12/14, Wrocław, Poland

5 Student Scientific Club No K 76, Department of Pharmaceutical Biology, Wroclaw Medical University, Borowska 211, 50-556 Wroclaw, Poland

\section{Introduction}

Moluccella laevis L. (Lamiaceae), also known as Irish bells, is an annual ornamental plant with green leafy calyces resembling goblets that surround the inconspicuous, fragrant white two-lipped corolla inside (Fardous et al. 2013). It is widespread throughout the world as garden and cut flower. So far, there have been no reports on culturing this species under controlled in vitro conditions. Among many tools used in classical biotechnology for plant multiplication, the various types of illumination and plant growth regulators (PGRs) are most commonly used. Light regime and culture media supplementation with PGRs influence growth, development and metabolism of plants (Batista et al. 2018). Optimizing of culture conditions may significantly increase the productivity of biomass and organ regeneration as well as the metabolic efficacy (Ogita et al. 2015; Espinosa-Leal et al. 2018; Isah et al. 2018; Matsura et al. 2018).

Therefore, in the present study, we examined the influence of exogenous phytohormones (BA, NAA, IAA and 
PIC, see "Materials and methods") and two light spectra ranges: $400-700 \mathrm{~nm}$ (white, W) and mix of $430 \mathrm{~nm}, 460 \mathrm{~nm}$, $610 \mathrm{~nm}, 630 \mathrm{~nm}, 660 \mathrm{~nm}, 730 \mathrm{~nm}$ (photosynthetically active radiation, PAR) on the growth and proliferation of $M$. laevis shoots as well as on secondary metabolite accumulation in tissue and organ cultures. The phytochemical analysis was performed using LC/MS technique.

\section{Materials and methods}

\section{Plant material}

Seeds of M. laevis derived from the certified collection of Botanical Garden of Medicinal Plants in Wroclaw, Poland ( $17^{\circ} 04^{\prime} 27^{\prime \prime} \mathrm{E}, 51^{\circ} 07^{\prime} 03^{\prime \prime} \mathrm{N}$, altitude $117 \mathrm{~m}$ a.s.1.) (under approval of the Ministry of Environment, Republic of Poland, Decision No. DOPogiz-4210-26-6024-/05/kl), were used to obtain cultures. Firstly, the seeds were surface sterilized for 10 min using 5\% sodium hypochlorite $(\mathrm{NaOCl})$, contained in a commercial preparation (bleach) $\mathrm{ACE}^{\circledR}$, and ethanol $96 \%$, rinsed three times in autoclaved distilled water, and sawn in Petri dishes on basal MS (Murashige and Skoog 1962) medium with $6 \mathrm{~g} / \mathrm{L}$ plant tissue culture grade agar (Biocorp, Poland).

\section{Shoot multiplication}

Nodes (3-5 mm long) containing two axillary buds, derived from 4-week-old aseptically growing seedlings, were used as explants for shoot multiplication. Explants were excised and transferred into 500-mL-volume culture jars (WECK Rundrand-glass 60, J. Weck \& Co, Germany) containing $100 \mathrm{ml}$ of shoot proliferation MS medium (two explants per one jar). The agar-solidified medium $(6 \mathrm{~g} / \mathrm{L})$ was supplemented with plant growth regulators (PGRs): 6-benzylaminopurine (BA) at a concentration of 2,3 or $4 \mu \mathrm{M}$ and one of the three auxins: 1-naphthaleneacetic acid (NAA), indole-3-acetic acid (IAA) or 4-amino-3,5,6-trichloropicolinic acid (picloram, PIC) which were added at a concentration of $0.5 \mu \mathrm{M}$. PGRsfree medium (MS0) was used as control. After 21 days of shoot culture, percentage of formation of axillary shoots (longer than $3 \mathrm{~mm}$ ), buds (shorter than $3 \mathrm{~mm}$ ) and their mean number per explant, the mean length $(\mathrm{cm})$ of single axillary shoot, and the diameter of callus tissue $(\mathrm{cm})$ formed at the basal part of shoots were determined.

\section{Culture conditions}

Shoot cultures were maintained in growth chamber at $25 \pm 0.5{ }^{\circ} \mathrm{C}, 40 \%$ of humidity under white $(W: 400-700 \mathrm{~nm}$,
$8000-10,000 \mathrm{~K})$ or Photosynthetically Active Radia-

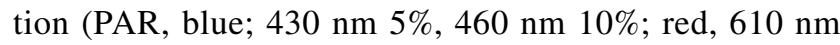

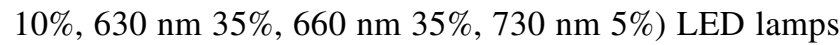
(Commled Solutions, Gliwice, Poland) at a photon flux density of $180 \mu \mathrm{M} \mathrm{m}^{-2} \mathrm{~s}^{-1}$ and 16/8-h (light/dark) photoperiod. The intensity of light was measured with a portable LightMeter HD 2302.0 equipped with LP 471 PAR and LP471 UVA detectors (DeltaOhm, Padova, Italy).

\section{Chlorophyll content}

Chlorophyll a and b contents (mg/g FW) were measured in proliferated shoots cultured on MS agar medium supplemented with BA $(2,3,4 \mu \mathrm{M})$ and NAA $(0.5 \mu \mathrm{M})$ using the Arnon method (1949). Briefly, $0.2 \mathrm{~g}$ of previously frozen plant material was weighed, triturated in a mortar-with the addition of calcium carbonate, sand and $3 \mathrm{~mL}$ of ethyl alcohol. When a homogeneous mixture was obtained, it was poured into a centrifuge tube. The extract was centrifuged at $4000 \mathrm{rpm}$ (max. acceleration $3280 \times g$ ) for $25 \mathrm{~min}$. The supernatant was poured into a clean tube and diluted four or eight times. The extracts from callus tissue were not diluted. The absorbance of the samples (against ethyl alcohol as a control) was measured by taking three measurements for each of them. The results were substituted for the chlorophyll a, b:

$$
\begin{aligned}
\text { Chlorophyll } \mathrm{a}= & {[(13.7 \times A 665)-(5.76 \times A 649)] } \\
& \times[V:(1000 \times W)] \times 4 \quad\left[\mathrm{mCla} \mathrm{g}^{-1} \text { fresh weight }\right], \\
\text { Chlorophyll } \mathrm{b}= & {[(25.8 \times A 645)-(7.6 \times A 665)] } \\
& \times[V:(1000 \times W)] \times 4 \quad\left[\mathrm{mgClb} \mathrm{g}^{-1} \text { fresh weight }\right],
\end{aligned}
$$

A $645 / 649 / 665$ is the absorbance value measured at a given wavelength; $V$ is the total volume of the extract $\left(\mathrm{cm}^{3}\right)$; $W$ is the sample weight $(\mathrm{g})$.

\section{Phytochemical analysis}

\section{Reagents and standards}

Acetonitrile, formic acid, methanol, standards of caffeic, and ferulic acids were purchased from Sigma-Aldrich (Steinheim, Germany); chlorogenic acid standard was from ICN Biomedicals (Costa Mesa, CA, USA); and rosmarinic acid standard was from Carl Roth (Karlsruhe, Germany).

\section{Extraction of phenolic compounds}

$100 \mathrm{mg}$ of lyophilized and ground plant material was weighed out and extracted with $2.5 \mathrm{~mL}$ of $100 \%$ methanol 
acidified with $0.1 \%$ formic acid in water $(4: 1 \mathrm{v} / \mathrm{v})$. The solution was placed in an ultrasonic bath for $15 \mathrm{~min}$, then filtered with a cotton filter and syringe and filtered into a clean tube. The remaining pellet was re-flooded with $2.5 \mathrm{~mL}$ of $100 \%$ methanol acidified with $0.1 \%$ formic acid solution and all operations were repeated. The filtered extracts were combined and store at $-18{ }^{\circ} \mathrm{C}$ until analysis was performed (for no longer than 3 days).

\section{UPLC-LC-MS analysis}

The analysis method was based on our previous paper (Zielińska et al. 2016). Composition of polyphenols in methanolic extracts was analyzed using an ACQUITY Ultra Performance LC system equipped with a photodiode array detector with a binary solvent manager (Waters Corporation, Milford, MA) and a G2 Q-TOF micro-mass spectrometer (Waters, Manchester, UK) equipped with an electrospray ionization (ESI) source operating in negative mode. Separation of individual polyphenols was carried out using a UPLC BEH C18 column $(1.7 \mu \mathrm{m}$, $2.1 \times 100 \mathrm{~mm}$, Waters Corporation, Milford, MA) at $30^{\circ} \mathrm{C}$. The samples $(10 \mu \mathrm{L})$ were injected, and the elution was completed in 15 min with a sequence of linear gradients and isocratic flow rates of $0.45 \mathrm{~mL} \mathrm{~min}{ }^{-1}$. The mobile phase consisted of solvent A ( $0.1 \%$ formic acid in water, $\mathrm{v} / \mathrm{v})$ and solvent $\mathrm{B}(0.1 \%$ formic acid in acetonitrile). The program began with isocratic elution with $99 \%$ solvent $\mathrm{A}$ and $1 \%$ solvent $\mathrm{B}(0-1 \mathrm{~min})$, and then a linear gradient was used for $12 \mathrm{~min}$, lowering solvent $\mathrm{A}$ to $0 \%$ and increasing solvent B to $100 \%$; from 12.5 to $13.5 \mathrm{~min}$, the gradient returned to the initial composition $(99 \%$ A, $1 \%$ B), and then it was held constant to re-equilibrate the column. The analysis was carried out using full-scan, datadependent MS scanning from $\mathrm{m} / \mathrm{z} 100$ to 2500. The optimized MS conditions were as follows: capillary voltage of $2500 \mathrm{~V}$, cone voltage of $30 \mathrm{~V}$, source temperature of $100{ }^{\circ} \mathrm{C}$, desolvation temperature of $300{ }^{\circ} \mathrm{C}$, and desolvation gas (nitrogen) flow rate of $300 \mathrm{~L} / \mathrm{h}$. Collision-induced fragmentation experiments were performed using argon as the collision gas, with voltage ramping cycles from 0.3 to $2 \mathrm{~V}$. Characterization of the single components was carried out via the retention time and the accurate molecular masses. Each compound was optimized to its estimated molecular mass in the negative mode, before and after fragmentation. The data obtained from UPLC-MS were entered into the MassLynx 4.0 ChromaLynx Application Manager software. Based on these data, the software is able to scan different samples for the characterized substances. The retention times and UV and mass spectra were compared to those of the authentic standards. Chlorogenic, caffeic, ferulic and rosmarinic acids were quantified with their own standards using detection at $320 \mathrm{~nm}$.

\section{Statistical analysis}

Data presented in the paper are means \pm standard error (SE) of three series of experiments in three subsequent subcultures (6-8 explants/passage/type of culture medium) for shoot cultures and 2 series of experiments per three samples $(n=6)$ for phytochemical analyses. The statistical analysis was carried out using the STATISTICA 13.1 program (StatSoft, 2016). Analysis of variance (ANOVA) and post hoc test of reasonable significant difference (Tukey test) were used to determine statistically significant differences in morphological traits of shoots, as well as in metabolite contents. Differences in pigment contents between samples were analyzed using a non-parametric Kruskal-Wallis test. The significance level in both tests were $p \leq 0.05$.

\section{Results}

\section{Shoot cultures}

Shoots of M. laevis showed the outbreak of lateral buds generated during the growth of cultured shoots under in vitro conditions on media containing PGRs. The effect of light regime was not statistically significant in terms of shoot formation. Plant growth regulators had a much greater impact on the formation of new shoots and the general condition of plants (Table 1).

All explants developed axillary shoots on MS medium supplemented with $2-\mu \mathrm{M}$ BA and $0.5-\mu \mathrm{M}$ NAA under both light spectra, but the initial mean number of axillary shoots gradually decreased along with the age of culture. The morphogenetic response of the shoots cultured on MS with $3 \mu \mathrm{M}$ BA and NAA $(0.5 \mu \mathrm{M})$ differed between white light and PAR; under the white light, a progressive degeneration of shoots occurred during the subculturing. The percentage of shoots developing new axillary buds and the mean number of shoots were also lower under white light (Table 1, Fig. 1c). Under PAR and on medium with BA $(3 \mu \mathrm{M})$ and NAA $(0.5 \mu \mathrm{M})$, the highest number of axillary shoots (3.4) was obtained and it was the highest number in this study (Table 1).

The increase of BA concentration to $4 \mu \mathrm{M}$ resulted not only in fast response in axillary shoots induction but also in faster senescence that was more pronounced under white light. Replacing NAA with IAA resulted in similar trend with respect to morphogenetic response to BA and illumination with mostly insignificant quantitative differences between these two auxins. On the other hand, new shoots developed on media with IAA, instead of NAA, had 


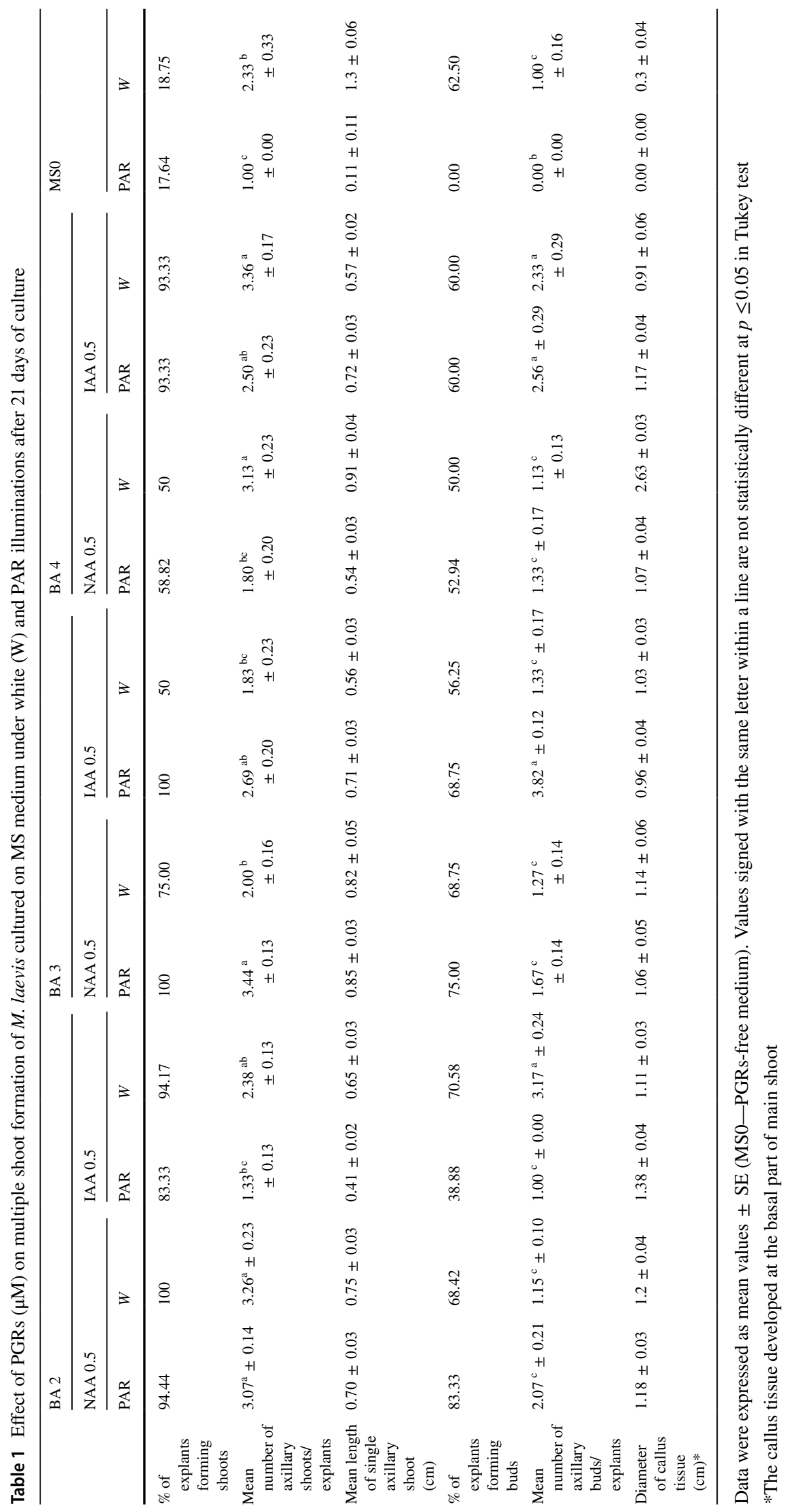



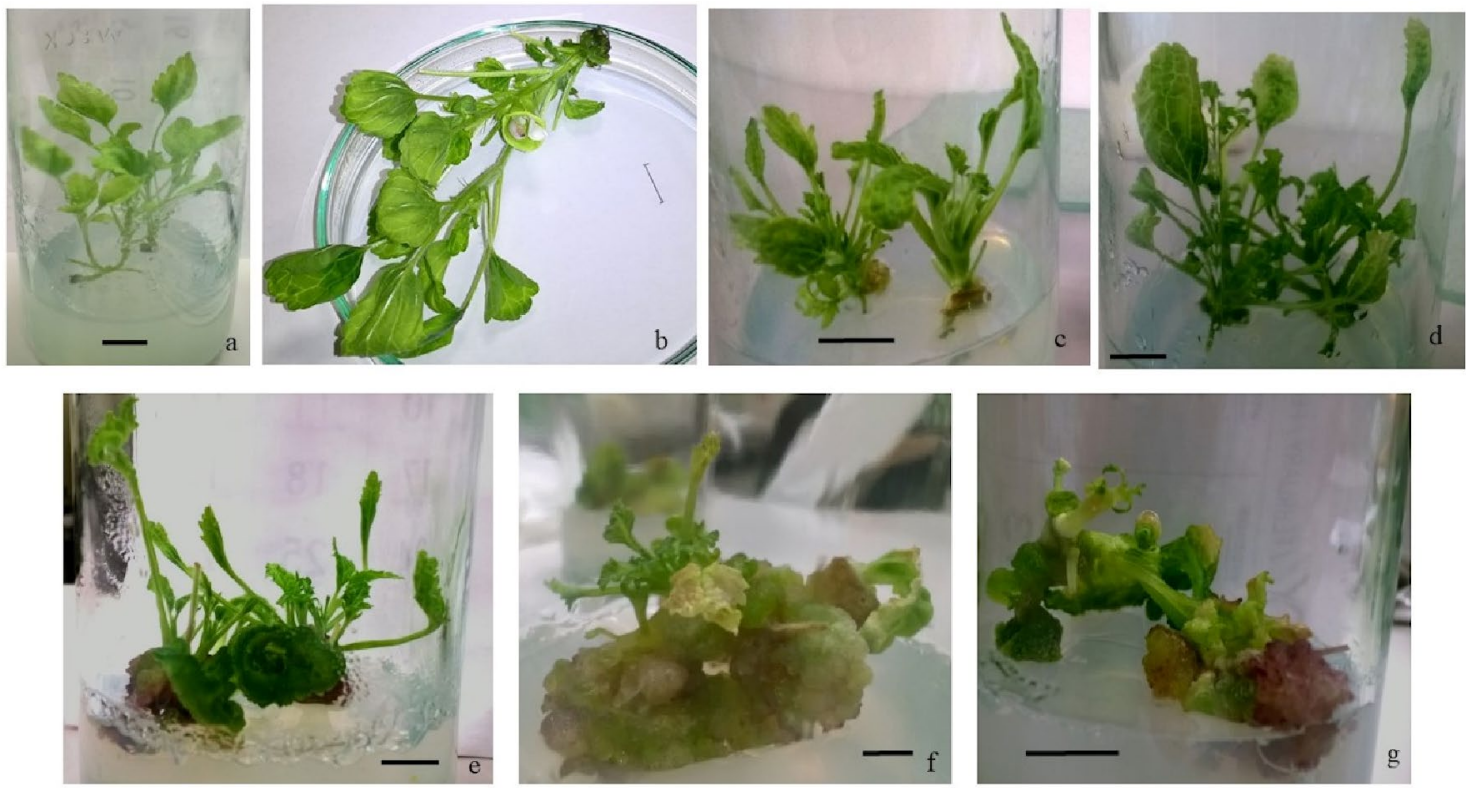

Fig. 1 M. laevis shoot cultures on PGRs-free medium (MS0) under PAR light after 21 days of culture (a), after 12 weeks of culture with sub-culturing (b); and after 21 days of culture on MS medium supplemented with: BA3 NAA0.5 $(\mu \mathrm{M})$ under white light $(\mathbf{c})$, BA3 NAA0.5

different leaf morphology. The leaf blades in the case of IAA were longer and narrower, and new shoots were thinner and smaller than those on NAA.

Shoots on BA and picloram $(0.5 \mu \mathrm{M})$ were morphologically abnormal. Explants did not develop axillary shoots, only buds with no leaves (Table 2, Fig. 1g). Nodal segments cultured on media with addition of lower concentration of BA $(2 \mu \mathrm{M})$ and PIC also formed callus at $(\mu \mathrm{M})$ under PAR light $(\mathbf{d})$, BA4 NAA0.5 $(\mu \mathrm{M})$ under white (e), BA4 NAA0.5 $(\mu \mathrm{M})$ under PAR light $(\mathbf{f})$, BA2 PIC0.5 $(\mu \mathrm{M})$ under PAR light (g); Scale bar: $1 \mathrm{~cm}$

their base, but the callus was not green, as in case of other media variants, but intensely purple colored (Fig. 1g).

Shoots cultured under PAR on most of media types except MS0, developed callus tissue at the basal part of explants (Table 1). The callus was light green, soft with no signs of organogenesis (Fig. 1f).

Table 2 Effect of BA $(2,3,4 \mu \mathrm{M})$ and PIC $(0.5 \mu \mathrm{M})$ on morphogenetic response and phenolic acids content (mg/100 g DW) in shoots of M. laevis cultured on agar MS medium under white (W) and PAR illuminations after 21 days of culture

\begin{tabular}{|c|c|c|c|c|c|c|}
\hline \multirow[t]{2}{*}{ Trial } & \multicolumn{2}{|l|}{ BA 2} & \multicolumn{2}{|l|}{ BA 3} & \multicolumn{2}{|l|}{ BA 4} \\
\hline & PAR & $\mathrm{W}$ & PAR & $\mathrm{W}$ & PAR & $\mathrm{W}$ \\
\hline$\%$ of explants forming shoots & 0 & 0 & 0 & 0 & 0 & 0 \\
\hline$\%$ of explants forming buds & 55.00 & 61.11 & 61.11 & 76.47 & 43.75 & 44.44 \\
\hline Mean number of buds & $1.18^{\mathrm{a}} \pm 0.12$ & $1.09^{\mathrm{a}} \pm 0.09$ & $1.09^{\mathrm{a}} \pm 0.09$ & $1.31^{\mathrm{a}} \pm 0.13$ & $1.00^{\mathrm{a}} \pm 0$ & $1.00^{\mathrm{a}} \pm 0$ \\
\hline Diameter of callus $[\mathrm{cm}]$ & $2.23 \pm 0.07$ & $1.67 \pm 0.10$ & $1.63 \pm 0.05$ & $1.39 \pm 0.08$ & $1.50 \pm 0.20$ & $1.37 \pm 0.06$ \\
\hline Chlorogenic acid & $0.80^{\mathrm{a}} \pm 0.007$ & $0.57^{\mathrm{b}} \pm 0.003$ & $0.49^{\mathrm{bd}} \pm 0.015$ & $0.23^{\mathrm{c}} \pm 0.009$ & $0.37^{\mathrm{cd}} \pm 0.009$ & $\begin{array}{l}0.25^{\mathrm{c}} \\
\quad \pm 0.004\end{array}$ \\
\hline Caffeic acid & $12.10^{\mathrm{a}} \pm 0.006$ & $14.12^{\mathrm{a}} \pm 0.009$ & $2.45^{b c} \pm 0.01$ & $1.60^{\mathrm{b}} \pm 0.008$ & $0.68^{d} \pm 0.009$ & $\begin{array}{l}3.17^{\mathrm{c}} \\
\quad \pm 0.050\end{array}$ \\
\hline Ferulic acid & $0.81^{\mathrm{a}} \pm 0.006$ & $0.20^{\mathrm{b}} \pm 0.004$ & $0.75^{\mathrm{a}} \pm 0.006$ & $0.10^{\mathrm{b}} \pm 0.005$ & $0.54^{\mathrm{a}} \pm 0.008$ & $\begin{array}{l}0.08^{\mathrm{b}} \\
\pm 0.005\end{array}$ \\
\hline Rosmarinic acid & $0.23^{\mathrm{a}} \pm 0.006$ & $0.16^{\mathrm{b}} \pm 0.007$ & $0.06^{\mathrm{c}} \pm 0.006$ & $0.09^{b c} \pm 0.008$ & $0.04^{\mathrm{c}} \pm 0.006$ & $\begin{array}{l}0.06^{\mathrm{c}} \\
\quad \pm 0.008\end{array}$ \\
\hline
\end{tabular}

Data were expressed as mean values \pm SE. Values signed with the same letter within a line are not statistically different at $p \leq 0.05$ in Tukey test 
Table 3 The content of chlorophyll a, b and a/b in shoots (mg/g FW $\pm \mathrm{SE}$ ) grown on media supplemented with different concentrations of BA $(2,3$, or $4 \mu \mathrm{M})$ and NAA $(0.5 \mu \mathrm{M})$ under two illuminations spectra: $W$ white light, $P A R$ photosynthetically active radiation, $M S O$ control PGRs-free medium

\begin{tabular}{llll}
\hline Treatment & Chlorophyll $\mathrm{a}^{*}$ & Chlorophyll $\mathrm{b}^{*}$ & $a / b$ ratio \\
\hline MS0 W & $0.61^{\text {ace }} \pm 0.0005$ & $0.12^{\mathrm{c}} \pm 0.0006$ & 5.08 \\
MS0 PAR & $1.69^{\mathrm{e}} \pm 0.0009$ & $0.19^{\mathrm{c}} \pm 0.0004$ & 8.89 \\
BA 2 W & $0.68^{\text {ace }} \pm 0.0004$ & $0.09^{\mathrm{a}} \pm 0.0002$ & 7.55 \\
BA 2 PAR & $0.36^{\text {acd }} \pm 0.0005$ & $0.02^{\mathrm{b}} \pm 0.0006$ & 18 \\
BA 3 W & $0.49^{\text {ace }} \pm 0.0003$ & $0.06^{\text {ab }} \pm 0.0003$ & 8.16 \\
BA 3 PAR & $0.60^{\text {ace }} \pm 6.35 \cdot 10^{-5}$ & $0.08^{\text {abc }} \pm 0.0002$ & 7.5 \\
BA 4 W & $0.54^{\text {ace }} \pm 0.0005$ & $0.059^{\text {ab }} \pm 0.0005$ & 9.15 \\
BA 4 PAR & $0.14^{\text {bd }} \pm 9.93 \cdot 10^{-5}$ & $0.02^{\mathrm{b}} \pm 0.0002$ & 7 \\
\hline
\end{tabular}

*Means with the same letter within each column are not statistically different at $p \leq 0.05$ by the Kruskal-Wallis test

Table 4 List of compounds detected in M. laevis shoot culture and their retention times (Rt), absorption maxima (DAD $\left.\lambda_{\max }\right), \mathrm{m} / \mathrm{z}$ $[\mathrm{M}-\mathrm{H}]^{-}$in negative mode

\begin{tabular}{llcc}
\hline Compound & $\lambda_{\max }(\mathrm{nm})$ & $\begin{array}{l}{[\mathrm{M}-\mathrm{H}]} \\
\mathrm{m} / \mathrm{z}\end{array}$ & $\mathrm{R} t(\mathrm{~min})$ \\
\hline Chlorogenic acid & 325 & 353.069 & 4.12 \\
Caffeic acid & 325 & 179.034 & 6.54 \\
Ferulic acid & 325 & 193.050 & 10.35 \\
Rosmarinic acid & 327 & 359.013 & 14.35 \\
Cyanidin 3- $O$-galactoside & 528 & 449.104 & 4.12 \\
Cyanidin 3- $O$-malonylglucoside & 528 & 535.106 & 5.32 \\
\hline
\end{tabular}

\section{Chlorophyll content}

The highest concentration of chlorophyll a $(1.69 \mathrm{mg} / \mathrm{g}$ $\mathrm{FW})$ and $\mathrm{b}(0.19 \mathrm{mg} / \mathrm{g} \mathrm{FW})$ was in shoot culture grown on medium without PGRs under PAR (Table 3). The chlorophyll contents were higher under white LED illumination than PAR, with the exception of medium with $3-\mu \mathrm{M}$ BA and 0.5- $\mu$ M NAA (Table 3).

Chlorophyll content was also determined in callus tissue that developed at the basal part of shoots (data not shown). The callus accumulated significantly lower amounts of chlorophylls compared to the values in shoots. The content of chlorophyll a under white light was between $0.003 \mathrm{mg} / \mathrm{g}$ FW on MS without PGRs and $0.059 \mathrm{mg} / \mathrm{g} \mathrm{FW}$ in callus cultured on MS medium with 3- $\mu \mathrm{M}$ BA and NAA. Chlorophyll b was between $0.021 \mathrm{mg} / \mathrm{g} \mathrm{FW}$ and $0.019 \mathrm{mg} / \mathrm{g} \mathrm{FW}$, respectively. Moreover, the chlorophyll content in callus was higher under PAR light conditions than white light (data not shown).

\section{Phytochemical analyses}

LC-MS profiling was used for identification of the compounds presented in methanolic extracts from shoot cultures and callus tissue of M. laevis grown in vitro under two lights spectra. The analysis showed the presence of two simple hydroxycinnamic acids (caffeic acid, ferulic acid), two conjugated caffeic acid derivatives (chlorogenic acid and rosmarinic acid) in shoots, and additionally in callus tissue two tentatively identified cyanidin glycosides (cyanidin 3-O-galactoside, and cyanidin 3-O-malonylglucoside) (Table 4). The assignment of cyanidin 3-O-galactoside (ideain) was based on the characteristic loss of a fragment of $\mathrm{m} / \mathrm{z} 448.107$ and $\mathrm{m} / \mathrm{z} 179.063$ attributed to deprotonated molecule of galactose. Identification of cyanidin 3-O-malonylglucoside was based on the characteristic loss of a fragment of $\mathrm{m} / z 535$ and $\mathrm{m} / \mathrm{z}, 448.107$ attributed to deprotonated molecule of cyanidin, and $\mathrm{m} / \mathrm{z} 287$ attributed to deprotonated molecule of malonylglucoside in negative mode (for the quantitative results, see Table 4).

\section{Discussion}

Shoot cultures of M. laevis were established using several combinations of exogenous auxins and cytokinins in the culture media (Fig. 1a-g, Tables 1 and 2). Different PGRs type and concentrations, as well as the spectrum of LED illuminations (white or PAR), demonstrated diverse response of the explants in terms of the outbreak of preformed buds, physiological condition reflected by differences in chlorophyll ( $a, b$, and $a / b$ ratio) and phenolic compounds contents.

The most effective concentration of BA for axillary shoot development was $3 \mu \mathrm{M}$. Shoots cultured on media with this concentration of BA developed leaves with normal morphology. The effect was stronger under PAR. BA at $2 \mu \mathrm{M}$ weakly stimulated shoot growth; whereas, the increase to $4 \mu \mathrm{M}$ BA resulted in degeneration of the shoots. However, no statistically significant differences regardless the light spectrum were noticed between shoots on media with $4 \mu \mathrm{M}$ BA and NAA or IAA (Fig. 1e) and $2 \mu \mathrm{M}$ BA and NAA.

For in vitro cultures of Physalis peruviana (Guney et al. 2016), Fragaria $\times$ ananassa (Sorvari et al. 1993), and Vitis vinifera (Jaskani et al. 2008) significantly higher concentrations of BA $(5,8$, and $12 \mu \mathrm{M})$ were used yielding higher shoot length, especially in combination with NAA and IBA at $0.5 \mu \mathrm{M}$ and $1 \mu \mathrm{M}$. On the other hand, higher levels of cytokinins are not beneficial for some other plant species. For example, in Ocimum basilicum shoot cultures the optimal growth was observed on media with $2 \mu \mathrm{M}$ BA, while higher concentrations of the cytokinin significantly limited the micropropagation of explants of the species (Saha et al. 2010). In in vitro cultured shoots of Plantago media, the 
BA concentration of $2.0 \mu \mathrm{M}$ in medium was optimal for both shoot development and content of phenolic metabolites (Budzianowska et al. 2019).

In our study, shoots cultured on medium without PGRs (MS0) under PAR, showed low morphogenetic ability. None of the explants produced buds nor callus tissue at the basal part of shoots, and only $17 \%$ of the explants developed single axillary shoots after 21 days of culture (Table 1, Fig. 1a). Interestingly, some shoots, which grew under PAR for 12 weeks on MS0 started to develop flowers (Fig. 1b). Similar phenomenon was earlier observed for $\mathrm{pRi}$-transformed plantlets of Centaurium erythraea after 12 weeks of growth on MS medium without PGRs (Piątczak et al. 2007). Moreover, M. laevis shoots cultured on MS0 under white light grew more vigorously than those under PAR. Conversely, the increased growth and survival of shoots was observed under PAR illumination in Brassica napus, Lactuca sativa, Raphanus sativus, and Spinacia oleracea (Ling et al. 2013; Shin et al. 2008; Yorio et al. 2001).

In axillary shoots on media supplemented with PGRs, the chlorophyll content was significantly lower than in shoots on MS0 medium (Table 3). This trend differs from many other species. For example, chickpea explants growing on PGR-containing media produced more chlorophyll than on PGR-free media. Kinetin (10 ppm) was the most stimulating, followed by 2,4,5-trichlorophenoxyacetic acid (5 ppm), 2,3,5-triiodobenzoic acid (25 ppm), and gibberellic acid (25 ppm) (Singh and Jain 1981). A stimulating effect of auxin NAA on chlorophyll production was also observed in Vigna mungo (Jeyakumar et al. 2008) and in maize by Rashad and Hussien (2014), who suggested the compensative effect of gibberellic acid $(100 \mathrm{mg} / \mathrm{L})$ against chlorophyll degradation in leaves caused by the irrigation of saline water.

The contrasting response of chlorophyll $a / b$ ratio to both light spectra depending on the BA concentration indicates a modulating effect of cytokinins on the photosynthetic/primary metabolism. Here, the higher $a / b$ ratio was under PAR at lower $(2 \mu \mathrm{M})$ and under white light at higher $(3$ or $4 \mu \mathrm{M})$ concentration of BA.

The interplay of chlorophyll biosynthesis and phytohormone flux are key in the light-regulated processes that are involved in the nutrient and metabolites allocation. Recent studies on the components that integrate light and hormone signaling pathways, indicated the involvement of transcription regulators such as elongated hypocotyl 5 protein, phytochrome-interacting factors (PIFs), ethylene insensitive three and DELLA proteins (characterized by motif: aspartate-glutamate-leucine-leucine-alanine or D-E-L-L-A in the single-letter amino acid code). Some of these components connect light signals to the signaling pathways of endogenous phytohormones, including ethylene, gibberellins and cytokinins (Liu et al. 2017). They have been recognized as integrators. According to these studies, to optimize the greening process, ethylene insensitive three directly activates the gene expression of light-dependent protochlorophyllide-reducing enzymes (PORA/PORB) and represses protochlorophyllide accumulation. The latter reaction is possible through activating phytochrome-interacting factors transcription; while, phytochrome B and constitutively photomorphogenic 1 (COP1), recognized as a central repressor of seedling photomorphogenesis, regulate mainly the levels of ethylene insensitive three. Moreover, phytochromeinteracting factors are crucial in the integration of light and gibberellin signals; while, the transcription activity of PIFs is sequestered by the repressors of gibberellins (DELLA proteins). Auxin and cytokinin regulate the elongated hypocotyl five protein stability and coordinate signals involved in root greening; whereas, ethylene, jasmonates and strigolactones regulate the nuclear localization of COP1, a possible new integrator (Liu et al. 2017).

In earlier studies of Kitajima and Hogan (2003), the adjustment of the chlorophyll $a-b$ ratio was probably an integral response related to the adaptation of the tested plants to high illumination and low nitrogen availability. The experiments were undertaken for seedlings of tropical woody plants that develop in limited light conditions and need to grow expansively in a short time to effectively use the incoming light. In this case, the initial nitrogen resources consumed for the needs of the young organism are essential. High light intensity often leads to the photosytem II damage in leaves observed in plants with low nitrogen resources. Based on the premise that chlorophyll $\mathrm{a} / \mathrm{b}$ ratio may indicate the nitrogen allocation in leaves, the results of Kitajima and Hogan (2003) showed that the chlorophyll a/b ratio was negatively correlated with leaf nitrogen in the presence of sun light. In shade, the chlorophyll $a / b$ ratio was uniformly low, regardless of nitrogen content. This was explained by the phenomenon of increased nitrogen investment to photosystem II, compared to Rubisco and photosystem II light harvesting complex, in high light environment and reduced availability of this element. However, examples of earlier studies on species from different environments showed that this is not general rule and that this type of research should consider individual ecological habitats (Kitajima and Hogan 2003).

The positive effect of PAR on the chlorophyll synthesis was observed in many previously published studies (Shin et al. 2008; Nhut et al. 2003). In turn, Kamiya et al. (1981) demonstrated the negative effect of red light on the chlorophyll precursors; whereas, blue light significantly increased chlorophyll synthesis. In our studies, chlorophyll content in callus tissue was much lower (data not shown) than in shoots, especially under white light conditions. The results were not surprising, as similar effect was earlier observed for example in Vicia faba cultures (Cësnienë et al. 2003). 


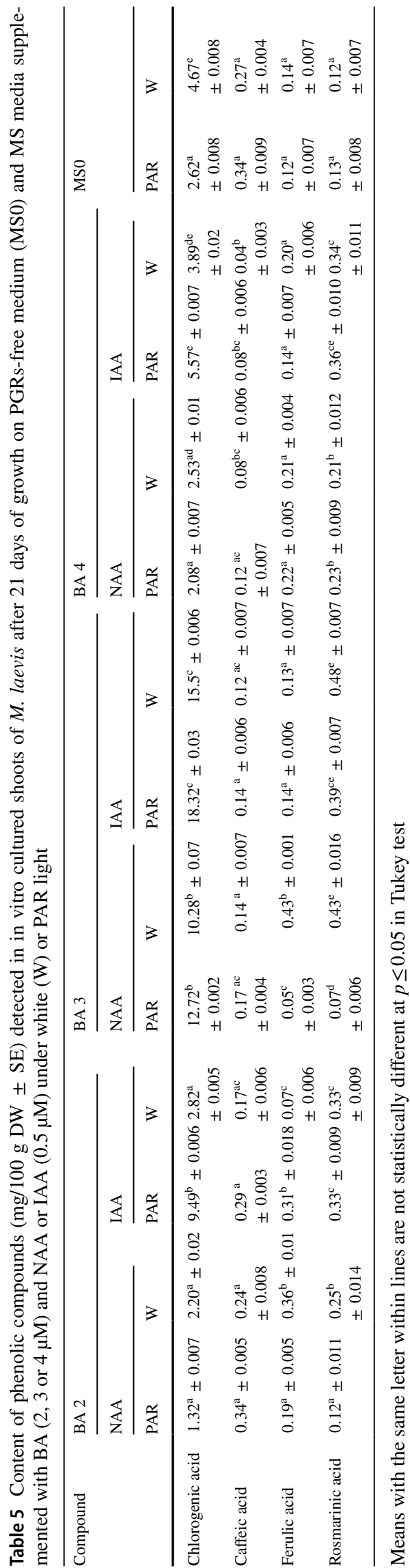

Many of the Lamiaceae species have been used for studying the production of phenolic compounds in various in vitro systems, such as cell suspension (WeremczukJeżyna et al. 2017), callus and shoot culture (Karakas and Turker 2016) or hairy roots (Grzegorczyk-Karolak et al. 2018). Usually, the yields were higher than in the shoot culture of M. laevis in our study. Addition of cytokinins and auxins influenced the content of major hydroxycinnamic acids much stronger than light spectrum. The highest contents of chlorogenic acid (15.5-18.32 mg/100 g DW) and caffeic acid (12.10-14.12 mg/100 g DW) were in extracts from shoots cultured under both illumination conditions (Table 5). In contrast, Chen et al (2016) boosted content of chlorogenic acid in Peucedanum japonicum calli by adding infrared wavelengths to the light spectrum. Conversely, in another Lamiaceae plant, Scutellaria lateriflora, the blue light induced significant increase in accumulation of phenolic metabolites (Kawka et al. 2017). Similar influence was noticed, for example, in Schisandra chinensis, Aronia melanocarpa, and Verbena officinalis (Szopa and Ekiert 2016; Kubica et al. 2017; Szopa et al. 2017, 2018). Hence, we suggest that increasing blue light fraction could be also beneficial for productivity of phenolic compounds in M. laevis cultures. These observations confirmed the well-known phenomenon of species-dependent differential metabolic response to the same conditions in vitro, including illumination spectrum (Samuoliene et al. 2017). The cellular mechanisms of these responses involve among others indirect influence on biosynthetic genes expression via photoreceptors or auxin responsive factors. However, the current knowledge on the topic is still too incomplete for drawing definite conclusions.

\section{Conclusions}

Using a classical biotechnology approach, it was possible to obtain shoot cultures of M. laevis. To our best knowledge, it has been the first report on the M. laevis shoots and callus cultured in vitro. Based on the results in our study, shoot cultures can be used for mass production of this beautiful ornamental plant. Moreover, the cultures were also able to accumulate phenolic compounds of medicinal and chemopreventive value, such as chlorogenic, caffeic, rosmarinic and ferulic acids. LED illumination spectra influenced the growth and development of shoots but the effect was hugely modulated by supplementation with plant growth regulators. Therefore, further investigations based on the genetic transformations or elicitation should be designed to increase biomass production and accumulation of bioactive phenolic metabolites. 
Author contribution statement SZ was responsible for investigations and writing the original draft and editing of the manuscript; EP was responsible for review and editing of the manuscript; WK, JKO, AB were responsible for methodology and conducting formal analysis; AJD was responsible for visualization of figures and tables; AM was responsible for the resources, supervision, review and editing of the manuscript.

\begin{abstract}
Acknowledgements This study was supported by the Wroclaw Medical University grant SUB.D033.19.009. The plant tissue culture laboratory received support from the Wroclaw Medical University Foundation (Fundacja Uniwersytetu Medycznego-FUM, Poland). Botanical Garden of Medicinal Plants receives support for special research facility from the Ministry of Science and Higher Education (MNiSW), Republic of Poland, decision No. 96/E394/SPUB/SP/2019.
\end{abstract}

Open Access This article is licensed under a Creative Commons Attribution 4.0 International License, which permits use, sharing, adaptation, distribution and reproduction in any medium or format, as long as you give appropriate credit to the original author(s) and the source, provide a link to the Creative Commons licence, and indicate if changes were made. The images or other third party material in this article are included in the article's Creative Commons licence, unless indicated otherwise in a credit line to the material. If material is not included in the article's Creative Commons licence and your intended use is not permitted by statutory regulation or exceeds the permitted use, you will need to obtain permission directly from the copyright holder. To view a copy of this licence, visit http://creativecommons.org/licenses/by/4.0/.

\section{References}

Arnon DI (1949) Copper enzymes in isolated chloroplasts Polyphenoloxidase in Beta vulgaris. Plant Physiol 24:1-15

Batista DS, Felipe SHS, Silva TD, DeCastro KM, Mamedes-Rodrigues TC, Miranda NA, Rios-Rios AM, Faria DV, Fortini EA, Chagas K, Torres-Silva G, Xavier A, Arencibia AD, Otoni WC (2018) Light quality in plant tissue culture: does it matter? Vitro Cell Dev Biol Plant 54:195-215

Budzianowska A, Kikowska M, Małkiewicz M, Karolak I, Budzianowski J (2019) Phenylethanoid glycosides in Plantago media L. organs obtained in in vitro cultures. Acta Biol Crac s Bot 61:75-86. https://doi.org/10.24425/118060

Cësnienë D, Barysas V, Rancelis L, Balciûnienë S, Dapkûnienë S (2003) Plant chlorophyll morphoses induced by $\mathrm{Co}\left(\mathrm{NO}_{3}\right)_{2}$. Chlorophyll content in leaves of intact plants and callus of Vicia faba. Biologija 1:45-49

Chen CC, Agrawal DC, Lee MR, Lee RJ, Kuo CL, Wu CR, Tsay HS, Chang HC (2016) Influence of LED light spectra on in vitro somatic embryogenesis and LC-MS analysis of chlorogenic acid and rutin in Peucedanum japonicum Thunb.: a medicinal herb. Bot Stud 57:9-17. https://doi.org/10.1186/s40529-016-0124-z

Espinosa-Leal CA, Puente-Garza CA, García-Lara S (2018) In vitro plant tissue culture: means for production of biological active compounds. Planta 248:1-18. https://doi.org/10.1007/s0042 5-018-2910-1

Minisi FA, El-mahrouk ME, Rida ME, Nasr MN (2013) Effects of gamma radiation on germination, growth characteristics and morphological variations of Moluccella laevis L. Am Eurasian J Agric Environ Sci 13:696-704
Grzegorczyk-Karolak I, Kuźma Ł, Skała E, Kiss AK (2018) Hairy roots of Salvia viridis L. for production of polyphenolic compounds. Ind Crops Prod 117:235-244

Guney M, Kafkas S, Kefayati S, Motalebipour E, Turkeli Y, Ercisli S, Kafkas E (2016) In vitro propagation of Physalis peruviana (L.) using apical shoot explant. Ogrodnictwo 15:109-118

Isah T, Umar S, Mujib A, Sharma MP, Rajasekharan PE, Zafar N, Frukh A (2018) Secondary metabolism of pharmaceuticals in the plant in vitro cultures: strategies, approaches, and limitations to achieving higher yield. Plant Cell Tissue Organ Cult 132:239-265. https://doi.org/10.1007/s11240-017-1332-2

Jaskani M, Abbas H, Sultana R, Khan M, Quasim M, Khan I (2008) Effect of growth hormones on micropropagation of Vitis vinifera L. CV. Perlette. Pak J Bot 40:105-109

Jeyakumar P, Velu G, Rajendran C, Amutha R, Savery M, Chidambaram S (2008) Varied responses of black gram (Vigna mungo) to certain foliar applied chemical sand plant growth regulators. Legume Res 31:110-113

Kamiya A, Ikegami I, Hase E (1981) Effects of light on chlorophyll formation in cultured Tobacco cells. Chlorophyll accumulation and phototransformation of protochlorophyll(ide) in callus cells under blue and red light. Plant Cell Physiol 22:1385-1396

Karakas FP, Turker AU (2016) Improvement of shoot proliferation and comparison of secondary metabolites in shoot and callus cultures of Phlomis armeniaca by LC-ESI-MS/MS analysis. Vitro Cell Dev Biol Plant 52:608-618. https://doi.org/10.1007/ s11627-016-9792-3

Kawka B, Kwiecień I, Ekiert H (2017) Influence of culture medium composition and light conditions on the accumulation of bioactive compounds in shoot cultures of Scutellaria lateriflora L. (American Skullcap) grown in vitro. Appl Biochem Biotechnol 183:1414-1425. https://doi.org/10.1007/s12010-017-2508-2

Kitajima K, Hogan KP (2003) Increases of chlorophyll a/b ratios during acclimation of tropical woody seedlings to nitrogen limitation and high light. Plant Cell Environ 26(6):857-865

Kubica P, Szopa A, Ekiert H (2017) Production of verbascoside and phenolic acids in biomass of Verbena officinalis L. (vervain) cultured under different in vitro conditions. Nat Prod Res 31:1663-1668. https://doi.org/10.1080/14786419.2017.1286477

Ling H, Tang C, Xu Z (2013) The effects of different light qualities on rapeseed (Brassica napus L.) plantlet growth and morphogenesis in vitro. Sci Hortic 50:117-124

Liu X, Li Y, Zhong S (2017) Interplay between light and plant hormones in the control of Arabidopsis seedling chlorophyll biosynthesis. Front Plant Sci 8:1433. https://doi.org/10.3389/ fpls.2017.01433

Matsuura HN, Malik S, de Costa F, Yousefzadi M, Mirjalili MH, Arroo R, Bhambra AS, Strnad M, Bonfill M, Fett-Neto AG (2018) Specialized plant metabolism characteristics and impact on target molecule biotechnological production. Mol Biotechnol 60:169-183. https://doi.org/10.1007/s12033-017-0056-1

Murashige T, Skoog F (1962) A revised medium for rapid growth and bioassays with tobacco tissue cultures. Physiol Plant $15: 473-497$

Nhut D, Takamura T, Watanabe H, Okamoto K, Tanaka M (2003) Responses of strawberry plantlets cultured in vitro under superbright red and blue light-emitting diodes (LEDs). Plant Cell Tissue Organ Cult 73:43-52. https://doi.org/10.1023/A:10226 38508007

Ogita S (2015) Plant cell, tissue and organ culture: the most flexible foundations for plant metabolic engineering applications. Nat Prod Commun 10:815-820

Piątczak E, Królicka A, Wysokińska H (2007) Genetic transformation of Centaurium erythraea Rafn by Agrobacterium rhizogenes and the production of secoiridoids. Plant Cell Rep 25:1308-1315. https://doi.org/10.1007/s00299-006-0155-0 
Rashad R, Hussien R (2014) A comparison study on the effect of some growth regulators on the nutrients content of maize plant under salinity conditions. Ann Agric Sci 59:89-94

Saha S, Ghosh P, Sengupta C (2010) An efficient method for micropropagation of Ocimum basilicum L. Indian J Plant Physiol 15:168-172

Samuoliene G, Brazaityte A, Vaštakaitè-Kairienè V (2017) Light-emitting diodes (LEDs) for improved nutritional quality. In: Dutta Gupta S (ed) Light-emitting diodes for agriculture. Springer, New York. https://doi. org/10.1007/978-981-10-5807-3-8

Shin K, Murthy H, Heo J, Hahn E, Paek K (2008) The effect of light quality on the growth and development of in vitro cultured Doritaenopsis plants. Acta Physiol Plant 30:339-343

Singh G, Jain S (1981) Effect of some growth regulators on certain biochemical parameters during seed development in chickpea under salinity. Indian J Plant Physiol 25:167-179

Sorvari S, Ulvinen S, Hietaranta T, Hiirsalmi H (1993) Preculture medium promotes direct shoot regeneration from micropropagated strawberry leaf disks. Hortic Sci 28:55-57

Szopa A, Ekiert H (2016) The importance of applied light quality on the production of lignans and phenolic acids in Schisandra chinensis (Turcz.) Baill. cultures in vitro. Plant Cell Tissue Org Cult 127:115-121

Szopa A, Kokotkiewicz A, Bednarz M, Luczkiewicz M, Ekiert $\mathrm{H}$ (2017) Studies on the accumulation of phenolic acids and flavonoids in different in vitro culture systems of Schisandra chinensis (Turcz.) Baill. using a DAD-HPLC method. Phytochem Lett 20:462-469. https://doi.org/10.1016/j.phytol.2016.10.016

Szopa A, Starzec A, Ekiert H (2018) The importance of monochromatic lights in the production of phenolic acids and flavonoids in shoot cultures of Aronia melanocarpa, Aronia arbutifolia and Aronia $\times$ prunifolia. J Photochem Photobiol B 179:91-97. https ://doi.org/10.1016/j.jphotobiol.2018.01.005

Weremczuk-Jeżyna I, Grzegorczyk-Karolak I, Frydrych B, HnatuszkoKonka K, Gerszberg A, Wysokińska H (2017) Rosmarinic acid accumulation and antioxidant potential of Dracocephalum moldavica L. cell suspension culture. Not Bot Horti Agrobot 45:215219. https://doi.org/10.15835/nbha45110728

Yorio N, Goins G, Kagie H (2001) Improving spinach, radish, and lettuce growth under red light-emitting diodes (LEDs) with blue light supplementation. Hort Science 36:380-383

Zielińska S, Kolniak-Ostek J, Dziadas M, Oszmiański J, Matkowski A (2016) Characterization of polyphenols in Agastache rugosa leaves and inflorescences by UPLC-qTOF-MS following FCPC separation. J Liq Chromatogr Relat Technol 39(4):209-219. https ://doi.org/10.1080/10826076.2016.1147461

Publisher's Note Springer Nature remains neutral with regard to jurisdictional claims in published maps and institutional affiliations. 